\title{
OPTIMALISASI PERAN ORANG TUA TERHADAP PENDIDIKAN SEKSUAL ANAK USIA DINI
}

\author{
${ }^{1}$ Aisyah, ${ }^{2}$ Isabella Hasiana \\ Fakultas Pedagogik dan Psikologi Universitas PGRI Adi Buana Surabaya \\ Email:aisyah@unipasby.ac.id, isabella@unipasby.ac.id
}

\begin{abstract}
ABSTRAK
Orangtua memiliki peran terhadap pendidikan anak mulai dari usia sejak di dalam kandungan hingga dewasa. Peran yang dilakukan oleh orang tua terhadap anak memiliki berbagai macam peraturan yang semuanya itu untuk memberikan pendidikan yang optimal bagi anak. Didalam program pengabdian pada masyarakat ini, memiliki tujuan untuk memberikan pengetahuan terhadap orang tua tentang pentingnya pendidikan seksual terhadap putra putrinya sejak di usia dini. Dalam hal pendidikan seksual tentu orangtua memiliki peran yang tidak sedikit. Orangtua harus menyadari bahwa dengan pendidikan seksual yang diterapkan sejak dini kepada anak, maka diharapkan anak akan terhindar dari perilaku-perilaku yang mengarah kepada kekerasan seksual. Peserta kegiatan pengabdian pada masyarakat ini ialah 25 wali murid TK Kristen Sejahtera. Pelaksanaan kegiatan menggunakan daring. Hasil yang didapatkan dari kegiatan pengabdian pada masyarakat ini ialah orangtua memiliki pengetahuan bahwa pendidikan seksual yang diberikan bukanlah hal yang tabu dan tentu saja yang diberikan kepada anak usia dini ialah sesuai dengan pemahaman kognitif mereka.
\end{abstract}

Kata kunci: Peran Orang Tua, Pendidikan seksual, anak usia dini

\begin{abstract}
Parents have a role in children's education starting from the age in the womb to adulthood. The role played by parents towards children has various kinds of regulations, all of which are to provide optimal education for children. In this community service program, the aim is to provide knowledge to parents about the importance of sexual eduation for their child from an early age. In terms of sexual education, of course parents have a significant role. Parents must realize that with ealry sexual education for children, it is hoped that children will avoid behaviors that lead to sexual violence. Participants in this community service activity were 25 parents of TK Kristen Sejahtera. Implementation of activites using online. The result obtained from this program is that parents have the knowledge that sexual education is not "tabu" and of course what is given to early childhood is in accordane with their cognitive understanding.
\end{abstract}

Keywords: the role of parents, sexual education, early childhood

\section{PENDAHULUAN}

Pertumbuhan dan perkembangan anak pada usia 0-6 tahun sangat membutuhkan perhatian dari orang tua atau orang yang mengasuhnya. Perkembangan anak yang perlu menjadi perhatian dari orangtua ialah yang terkait dengan pendidikan seksual.
Kenyataan yang ada di sekitar kita saat ini ialah semakin tingginya kasus kekerasan tentang seksual yang menimpa anak usia dini. Ironisnya, justru tidak menutup kemungkinan bahwa pelaku kekerasan seksual ini merupakan orang dekat atau orang yang dikenal anak dalam kesehariannya. 
Kasus kekerasan seksual yang dialami oleh anak usia dini di sebuah sekolah internasional di jakarta pada tahun 2014, tentu membuat terkejut dunia pendidikan khususnya pendidikan anak usia dini. Pada dasarnya, kekerasan seksual ini berkembang sangat pesat hanya saja tidak semua korban kekerasan mau mengadukan permasalahannya kepada pihak hukum. Alasannya antara lain, untuk menjaga nama baik keluarga (jika pelakunya adalah anggota keluarga), ataupun untuk menjaga dampak yang akan dialami oleh anak (korban) jika masalah ini sampai ke ranah hukum.

Oleh sebab itu, kegiatan pengabdian pada masyarakat ini dilakukan dengan tujuan memberikan pengetahuan terhadap orangtua tentang pentingnya memberikan pendidikan seksual terhadap anak sejak usia dini. Supaya anak berkembang menjadi pribadi muda berkualitas, maka orang tua memberikan pengetahuan tentang seksual sejak usia kecil, agar anak mampu menjaga dan melindungi anggota badan yang tidak boleh dipegang atau disentuh oleh siapa saja.

Keluarga merupakan unit atau bagian terkecil dari masyarakat, dan terdiri dari ayah dan ibu tentu memiliki peran penting dalam perkembangan anaknya dan tentu akan sangat berpengaruh bagi masa depan anak tersebut. Anak adalah masa depan, dan tidak sedikit juga orangtua yang mengatakan bahwa anak adalah aset mereka yang paling berharga. Berkaitan dengan hal tersebut, tentu orangtua memiliki kewajiban untuk menyediakan masa depan yang baik bagi mereka. Masa depan tersebut tentu saja tidak hanya dari segi materi, melainkan juga dari segi psikologis, kesehatan, pendidikan dan religius anak (Ainys \& Warsiti, 2017).

Dalam memberikan pendidikan tentang seksual terhadap anak usia dini tentu saja bukan hanya dituntut peran dari orang tua, namun pihak sekolah juga memiliki peran dan tugas untuk dapat menjelaskan tentang pengetahuan seksual yang mudah dipahami anak melalui pembelajaran. Pihak sekolah harus melibatkan orang tua untuk berperan penting dalam pendidikan seksual di lingkungan keluarga dan lingkungan tempat tinggalnya untuk menghindari sesuatu yang tidak diharapkan, dengan kata lain orangtua juga perlu ada keterlibatan dalam proses tersebut.

Berdasarkan hasil survey yang diberikan kepada orangtua, sebanyak 45\% orangtua menganggap tabu untuk membicarakan seksual kepada anak, sebanyak $27 \%$ mengatakan penting untuk mengajarkan tentang pendidikan seks, $18 \%$ mengatakan tidak terlalu penting, dan yang $10 \%$ tidak tahu apa yang dimaksud pendidikan seks.

Teknologi pada masa ini juga berkembang sangat pesat dan akan menjadi kekhawatiran yang muncul jika anak tidak dibekali dengan pendidikan seks yang tepat dari keluarga, maka tidak menutup kemungkinan anak akan memperoleh pengetahuan tersebut melalui media elektronik dan dengan mudah untuk mengakses informasi melalui situs yang tidak tepat.

Oleh sebab itu perlu pengawasan dan pendampingan yang tepat terhadap anak, agar orangtua dapat memberikan arahan terkait tentang informasi-informasi yang sesuai dengan usianya. Selain itu pendidikan seks yang diberikan secara tepat akan meminimalisir anak menjadi korban pelecehan seksual.

Anak hendaknya mendapatkan pendidikan tentang seksual sejak dini untuk mencegah berkembangnya pikiran-pikiran negatif pada anak, terutama apabila sudah mulai mengenal informasi dari media seperti televisi, internet dan sebagainya. Oleh sebab itu peran dari orang tua harus lebih dioptimalkan dalam mendidik dan mengasuh anak di jaman yang sudah sangat berkembang dalam mengunakan teknologi yang sudah mudah dipahami oleh anak sejak usia dini.

Menurut Adi (2005) pendidikan seksual merupakan suatu upaya dalam memberikan pengetahuan kepada seorang anak berkaitan dengan kondisi fisik sebagai perempuan dan laki-laki serta keadaan secara psikologis yang akan dialami oleh anak. Oleh sebab itu, pemberian pengetahuan tersebut 
akan meminimalisir terjadinya pergaulan bebas serta pencegahan peristiwa pelecehan seksual (Priyatna, 2015).

Selain itu secara garis besar, pendidikan seks (sex education) diartikan sebagai pendidikan tentang tingkah laku yang baik, dan adanya nilai moral di dalam masyarakat yang dijunjung tinggi serta upaya untuk menolong individu dalam mengatasi persoalan hidupnya yang terpusat pada naluri seks. Dari artian kalimat tersebut maka dapat dikatakan bahwa pendidikan seks dilakukan untuk memberikan pencerahan tentang apapun yang berkaitan dengan seks dan seksualitas dan tentunya hal tersebut dilakukan dalam batasan yang wajar serta pengetahuan yang tidak terbatas tentang anatomi, fisiologi, penyakit kelamin dan penyimpangan perilaku seksual. Dan yang terpenting dari semuanya itu ialah untuk membentuk sikap dan perilaku seseorang terhadap seks itu sendiri.

Pengetahuan tentang seks kepada anak usia dini dilakukan untuk mengedukasi mereka dalam memahami kondisi tubuhnya, bagaimana harus berperilaku kepada lawan jenis (misalnya, tidak boleh sembarangan peluk atau cium kepada lawan jenis), dan memahami bagaimana cara untuk menghindar dari kemungkinan terjadinya tindakan kekerasan seksual atau dengan kata lain menghindar dari perilaku yang mengarah pada terjadinya kekerasan seksual (Panjaitan, Djuanda, \& Hanifah, 2015).

Pada dasarnya dalam membicarakan seksualitas tidak hanya berhubungan dengan "mengumbar anggota badan secara sembarangan" atau mengajarkan tentang cara melakukan hubungan seks dan tentu saja bukan pula hanya sekedar untuk membicarakan tentang alat kelamin. Tetapi seksualitas berkaitan dengan peran kita sebagai laki-laki dan perempuan (Yafie, 2017).

Sebagaimana yang disampaikan oleh Ulwan dan Hathout (Yafie, 2017) yang membagi menjadi beberapa tahapan usia untuk mengenalkan pendidikan seks kepada anak, yaitu: a. Usia 7-10 tahun, anak diajarkan tentang sopan santun bila memasuki rumah dan sopan santun dalam memandang orang lain.

b. Usia 10-11 tahun, anak sudah memasuki masa pubertas dan yang perlu diajarkan adalah bagaimana anak menjauhkan diri dari hal-hal yang menumbuhkan birahi.

c. Usia 14-16 tahun, adalah usia remaja. Pada usia ini anak perlu diajarkan tentang etika bergaul dengan lawan jenis

d. Pada saat anak memasuki usia pemuda, maka diajarkan tentang menahan diri (dari nafsu)

Dampak yang akan terjadi pada anak di masa depannya apabila ia diberikan pendidikan seks sejak usia dini ialah akan berpengaruh terhadap perilakunya saat anak memasuki usia remaja. Penelitian yang dilakukan oleh Septiawan (2014) berkenaan dengan hal tersebut diatas menyatakan bahwa remaja yang tidak mendapatkan pengetahuan tentang pendidikan seksual yang tepat dari keluarga (orangtua) maka ada kecenderungan untuk mencari tahu informasi tersebut dari teman sebaya yang kemungkinan besar juga tidak tahu, sehingga hal ini membuat mereka akan mendapatkan pemahaman yang kurang tepat serta ada kecenderungan terjadinya penyimpangan seksual.

Beberapa penelitian yang terkait dengan pendidikan seksual juga menyatakan bahwa saat remaja mendapatkan pendidikan seksual yang tepat, akan menyebabkan mereka memiliki gaya pacaran yang sehat dibandingkan remaja yang tidak mendapatkan pendidikan seks.

\section{METODE PELAKSANAAN}

Metode pelaksanaan dalam program pengabdian pada masyarakat ini melalui beberapa tahapan, yaitu: (1). Melakukan analisis situasi terhadap kondisi yang ada di lapangan; (2). Menggali informasi yang mendalam melalui wawancara dan angket yang diberikan kepada orangtua kelompok B siswa TK Kristen Sejahtera yang berusia 
sekitar 5-6 tahun, serta juga dilakukan kepada semua guru di TK Kristen Sejahtera.; (3). Melakukan kegiatan parenting pengabdian masyarakat dengan menggunakan daring yang diikuti oleh 25 orangtua murid dan 6 guru dari TK Kristen Sejahtera.

\section{HASIL DAN PEMBAHASAN}

Tim Pengabdian

berupaya mengeksplorasi kondisi TK Kristen Sejahtera melalui observasi langsung dan angket.

Adapun materi yang disampaikan meliputi: (1). Tahapan perkembangan seksual pada anak, (2). Pendidikan seksual pada anak, (3). Cara orangtua dalam memberikan pendidikan seksual pada anak. Meskipun kegiatan dilakukan secara daring, namun antusias orangtua dalam mengikuti kegiatan ini sangat baik. Banyak sekali pertanyaan yang muncul, antara lain (1). sejak usia kapan pendidikan seks diberikan?, (2) jika dianggap penting mengapa tidak dimasukkan di dalam kurikulum.

Pertanyaan tersebut dijawab pemateri berdasarkan pemahaman dan pengalaman yang dimiliki. Pada pertanyaan pertama tentang sejak usia kapan anak diberikan pendidikan seks, pemateri memberikan penjelasan bahwa menurut perkembangan psikoseksual, maka pemberian pendidikan seks sebaiknya dilakukan mulai dari anak usia 1 tahun dan harus dilakukan sesuai dengan tingkat pemahaman anak.

Pemateri memberikan penjelasan terkait dengan masuknya pendidikan seksual di kurikulum yang memang tidak secara terang-terangan ada dalam kurikulum namun masuk dalam kegiatan pembelajaran. Misalnya pada tema diri sendiri, guru memasukkan dengan cara menjelaskan tentang anggota tubuh anak yang boleh disentuh dan tidak boleh disentuh atau ditunjukkan kepada orang lain.

Ada kekhawatiran dari para Orang tua murid di TK Kristen Sejahtera yang hampir sebagian besar bekerja di luar rumah tentang pemberian pendidikan seksual pada anak sedangkan anak diasuh oleh pengasuh ataupun keluarga lain (nenek). Dengan demikian perkembangan dan pertumbuhan anak lebih banyak didampingi oleh pengasuhnya antara lain ada yang di asuh baby siter, asisten rumah tangga, neneknya, tantenya dan ada pula tetangganya yang berfungsi sebagai tempat atau lembaga penitipan anak.

Pemateri menjelaskan bahwa pemberian pendidikan seksual memang ada pada orangtua, namun orangtua dapat bekerja sama dengan pengasuh anak untuk memberikan edukasi juga terhadap anak. Misalnya dengan lagu. Ada lagu tentang sentuhan boleh dan tidak boleh yang cukup mudah untuk diikuti baik oleh anak, orangtua maupun pengasuh.

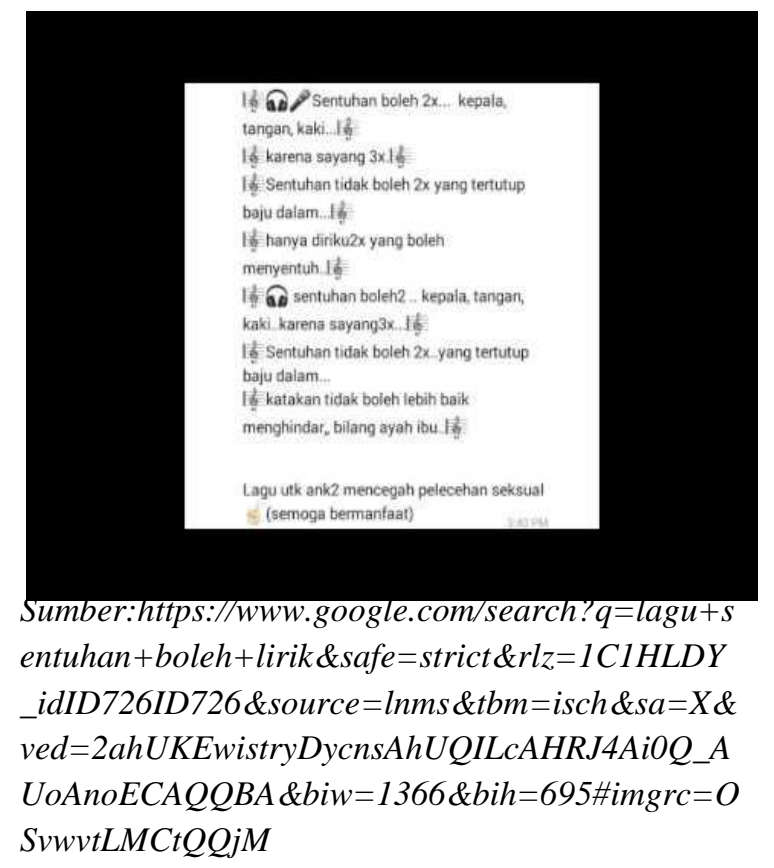

Untaian kalimat lagu diatas adalah lirik lagu yang berjudul Sentuhan boleh Sentuhan Tidak Boleh karya Sri Seskya Situmorang dan dinyanyikan oleh Indri Ayu Lestari

(https://www.kompasiana.com/deardarrel1/59f c344ec226f9101c20d023/sentuhan-bolehsentuhan-tidak-boleh).

Lewat lagu diatas, orangtua serta pengasuh akan lebih mudah untuk menjelaskan tentang pendidikan seksual kepada anak. 
Tim parenting pengabdian masyarakat memberikan solusi terhadap orang tua supaya dapat mengoptimalkan perannya sebagai orang tua dalam memberikan informasi penyampaian pengetahuan tentang pendidikan seksual terhadap anak-anak mereka. Tugas tersebut tidak hanya dibebankan kepada guru saja tetapi orang tua juga harus terlibat dalam memberikan informasi tentang perkembangan seksual anaknya. Pemberian pendidikan tentang seksual sejak usia dini sangat bermanfaat bagi perkembangan dan pertumbuhan fisik dan psikologis anak dimasa mendatang. Seperti halnya yang disampaikan oleh Boyke dalam jurnal Perlunya Pendidikan Seks Pada Anak Sejak Usia Dini yang menerangkan bahwa pendidikan seks untuk anak digolongkan dalam 4 tahapan berdasarkan rentang usianya, yaitu usia 1-4 tahun, usia 5-7 tahun, usia 8-10 tahun dan usia 10-12 tahun.

Pada usia 1-4 tahun, orang tua diharapkan mengenalkan kepada anak tentang anatomi tubuh manusia sampai ke alat genital. Orangtua mengenalkan kepada anak, ini mata, ini kaki, ini vagina dengan bahasa yang sebenarnya dan tidak menggunakan istilah lain agar ketika anak memasuki usia remaja, ia tidak akan takut untuk menyebutkannya.

Pada usia 5-7 tahun keingintahuan anak tentang seksual biasanya semakin bertambah. Di usia ini akan muncul pertanyaan-pertanyaan tentang perbedaan bagian anggota badan yang berbeda dengan dirinya sendiri. Rasa ingin tahu itu adalah sesuatu hal yang wajar. Untuk menyikapi hal tersebut, orangtua dapat lebih bersikap sabar dan komunikatif serta memberikan penjelasan tentang hal-hal yang ingin diketahui anak sesuai dengan tingkat pemahamannya. Sebagai contoh kasus, jika anak laki-laki dengan sengaja membuka rok teman perempuannya, entah itu sebagai tindakan yang iseng atau ingin tahu, tindakan orangtua maupun guru jangan hanya ditegur atau dimarahi lalu ditinggalkan tanpa penjelasan. Orangtua harus menjelaskan mengapa hal itu tidak boleh dilakukan.
Berdasarkan hal diatas, maka dapat dikatakan bahwa dalam menyampaikan pendidikan seksual kepada anak usia dini dapat diperoleh dengan gampang. Akses atau informasi untuk tentang hal tersebut sudah berkembang dengan pesat. Hanya memang diperlukan peran dan kerjasama dari orangtua dan pihak sekolah untuk memberikan edukasi kepada anak.

\section{KESIMPULAN DAN SARAN}

Kegiatan pengabdian pada masyarakat yang memiliki tema optimalisasi peran orangtua dalam pendidikan seksual anak usia dini telah terlaksana dengan baik dan ada kerjasama serta interaksi antara pihak sekolah, orangtua maupun pengasuh dalam mengajarkan pendidikan seksual tersebut. Anak mendapat pengetahuan pendidikan seksual sesuai dengan tingkat pemahamannya. Selain itu guru dan orangtua tidak lagi merasa tabu jika membicarakan tentang pendidikan seksual.

Selanjutnya perlu diadakan lagi kegiatan semcama ini yang terprogram untuk memperoleh pengetahuan yang lebih mendalam tentang pendidikan seksual pada anak dan kegiatan yang serupa juga perlu diadakan di tempat lain agar semakin banyak orangtua dan guru yang memahami bahwa pentingnya pendidikan seksual diberikan kepada anak sejak usia dini untuk mencegah dan mengurangi terjadinya tindakan kekerasan seksual pada anak.

\section{DAFTAR PUSTAKA}

Adi. 2005. Pendidikan Seks. Yogyakarta: Curosita

Ainys, A. N., \& Warsiti. (2017). Gambaran Peran Orang Tua Dalam Memberikan Pendidikan Seks Dini Di Kelompok Bermain 'Aisyiyah Rejodani, Sleman Menurut Perspektif Islam. Retrieved from

http://digilib.unisayogya.ac.id/2501/1/nas kah publikasi aisyah nur ainys 201310201002.pdf

Panjaitan, R. L., Djuanda, D., \& Hanifah, N. 
(2015). Persepsi Guru Mengenai Sex Education Di Sekolah Dasar Kelas Vi, 2(2), 224-233. https://doi.org/10.17509/mimbarsd.v2i2.1332

Priyatna. 2015. Stop It Now. Jakarta: PT. Gramedia

Priyatna. 2015. Pelecehan Seksual Anak Cegah Sebelum Terjadi. Jakarta: PT Elex Media Komputindo kelompok Gramedia Yafie, E. (2017). PENDIDIKAN SEKSUAL ANAK USIA DINI Jurnal CARE ( Children Advisory Research and Education ) Volume 4 Nomor 2 Januari 2017

https://www.kompasiana.com/deardarrell/59fc 344ec226f9101c20d023/sentuhan-bolehsentuhan-tidak-boleh

http://digilib.unisayogya.ac.id/2501/1/naskah $\% 20$ publikasi\%20aisyah\%20nur\%20ainy s\%20201310201002.pdf 
